\title{
IMPROVED WEAR ON FEED CHANNEL OF GRAVITY CASTING MOLDS
}

\section{Bianca Nunes Moura ${ }^{1}$, Allan Thiago Moura², Ana Emília Diniz Silva Guedes ${ }^{3}$, Anderson de Oliveira Castro $^{4}$}

${ }^{1,2}$ Discente em Engenharia Mecânica pelo Centro Universsitário do Norte (UNINORTE). Manaus - Am.

${ }^{3}$ Coordenadora do curso de Engenharia Mecânica no Centro Universsitário do Norte (UNINORTE). Manaus - Am.

${ }^{4}$ Professor de TCC no Centro Universsitário do Norte (UNINORTE). Manaus - Am.

Email: bianca_nmoura@outlook.com, thiagomouraallan@gmail.com, anderson.castro@uninorte.com.br, ana.guedes@uninorte.com.br

Received: May 24th, 2019

Accepted: June 25th 2019

Published: September 30th, 2019

Copyright $(C 2016$ by authors and Institute of Technology Galileo of Amazon (ITEGAM). This work is licensed under the Creative Commons Attribution International License (CC BY 4.0). https://creativecommons.org/lice nses/by/4.0/

\section{(c) (i) Open Aceses:}

\begin{abstract}
In order to reduce wear and costs with replacement parts of the mold, analyzes were carried out in the casting process of the wheel, and through the Quality Tools it was observed that the feed channel (pouring cup) of the mold was more frequent than other parts. To assess the cause of wear, the Cause and Effect ( $4 \mathrm{~m}$ 's) diagram was used and it was found that steel in which the mold was manufactured did not have sufficient properties to withstand the temperature that aluminum was deposited in the mold, causing thermal cracking and premature wear of the part (pouring cup), needing to be manufactured with more resistant material that is the cast iron, raising its performance. With the implementation of the project, several positive results were obtained: $88 \%$ decrease in the annual cost of spare parts; reduction of $90 \%$ waste of raw material; decrease in waste generation and a $500 \%$ increase in leak-cup resistance.
\end{abstract}

Keywords: Casting, Mold, Alloy Wheel, Pouring Cup, Cast Iron.

\section{MELHORIA DO DESGASTE NO CANAL DE ALIMENTAÇÃO DOS MOLDES DE FUNDIÇÃO POR GRAVIDADE}

\begin{abstract}
RESUMO
Com o objetivo de diminuir desgastes e custos com peças de reposição do molde, realizou-se análises no processo de fundição da roda, e através das Ferramentas da Qualidade foi observado que o canal de alimentação ( copo de vazamento ) do molde desgastava com mais frequência do que outras peças. Para avaliar a causa do desgaste, usou-se o diagrama de Causa e Efeito (4m's) e constatou-se que aço em que o molde era fabricado, não tinha propriedades suficientes para suportar a temperatura que alumínio era depositado no molde, ocasionando trincas térmicas e desgaste prematuro da peça (copo de vazamento), precisando ser fabricado com material mais resistente que é o ferro fundido, elevando seu desempenho. Com a implantação do projeto, obteve-se diversos resultados positivos como: Diminuição em $88 \%$ do custo anual com peças de reposição; redução de $90 \%$ desperdício de matéria prima; diminuição de geração de resíduos e o aumento de $500 \%$ na resistência do copo de vazamento.
\end{abstract}

Resumo: Fundição, Molde, Roda de Liga Leve, Copo de Vazamento, Ferro Fundido.

\section{INTRODUÇÃO}

Existem vários processos diferentes para se produzir peças fundidas, os mais comuns são: fundição por gravidade, por centrifugação, sob pressão e de precisão. Cada um se ajusta a determinadas exigências de qualidade, custo e tempo. Mas, basicamente, o início do processo, é a produção de um modelo ou de um molde [1].
Fundição de alumínio por gravidade é o processo cujo o alumínio em seu estado liquido é depositado no molde sem qualquer ajuda de força externa, somente com o auxílio da força gravitacional [3].

A turbulência no canal de descida e falta de pressão para garantir a alimentação, particularmente em ligas de solidificação pastosa, são problemas do processo de vazamento sob gravidade [6]. 
Moldes usados para fundição de ligas não ferrosas estão sujeitos a várias cargas térmicas e mecânicas, que exigem altas propriedades do molde. Existem inúmeros fenômenos que restringem a vida útil, os mais importantes são: Fadiga térmica, Erosão, Ataque do Alumínio e Trincas catastróficas [9] [10].

\section{I.1 FADIGA TÉRMICA}

A Fadiga Térmica em moldes de fundição de alumínio ocorre em razão do molde estar sempre a uma temperatura significativamente inferior à da liga de alumínio que está sendo injetada. Consequentemente a superfície de trabalho da ferramenta é submetida a uma dilatação seguida de uma contração a cada ciclo de injeção. Estas tensões mecânicas induzidas termicamente levam a nucleação e propagação de trincas térmicas, que são trincas perpendiculares à superfície. Para um controle mais efetivo das trincas térmicas é necessária uma escolha adequada do aço e especialmente do tratamento térmico aplicado [8].

\section{2 FERRAMENTAS DA QUALIDADE}

As ferramentas da qualidade são métodos utilizados para a melhoria de processos e solução de problemas. O uso dessas ferramentas tem como objetivo a clareza no trabalho e principalmente a tomada de decisão com base em fatos e dados, ao invés de opiniões [17], são ferramentas da qualidade: Folha de Verificação é uma planilha para o registro de dados [18]; Segundo [19] O Diagrama de Pareto é usado quando é preciso dar atenção aos problemas de uma maneira sistemática; Diagrama de Causa Efeito ( Ishikawa ) mostra a relação entre uma característica da qualidade e os fatores [20]; [21] menciona que a planilha 5W2H ou 4Q1POC é uma ferramenta que auxilia no planejamento das ações que for desenvolver, ele é constituído de um relatório por colunas, cada uma delas acompanhadas por um título, palavras da língua inglesa: Why (Por que?), What (O que?), Who (Quem?), When (Quando?), Where (Onde?), How (Como?) e How Much (Quanto?).

\section{DESENVOLVIMENTO}

\section{II.1 MATERIAL E MÉTODO}

Em uma determinada empresa do distrito industrial de Manaus, responsável por produção de motocicletas de até 300 cilindradas, realizou-se análises no processo de fundição da roda de liga leve.

O processo de fundição da roda, inicia com a fusão do alumínio no forno fusor, onde o alumínio no estado solido passa para liquido, em seguida o alumínio liquido é transportado para o forno de espera, logo após, um braço robótico irá retirar o alumínio liquido do forno de espera e fará o vazamento no molde de fundição da roda. O processo de fundição pode gerar rebarbas, que são projeções indesejáveis de material [11], sendo assim a roda precisa fazer a retirada dessas rebarbas no processo de acabamento. Visando aumentar a dureza da roda fundida [12] é realizado o tratamento térmico. A usinagem deixará a roda nas dimensões desejadas, por fim a roda é pintada e montada. Processos esses demonstrados na Figura 1.

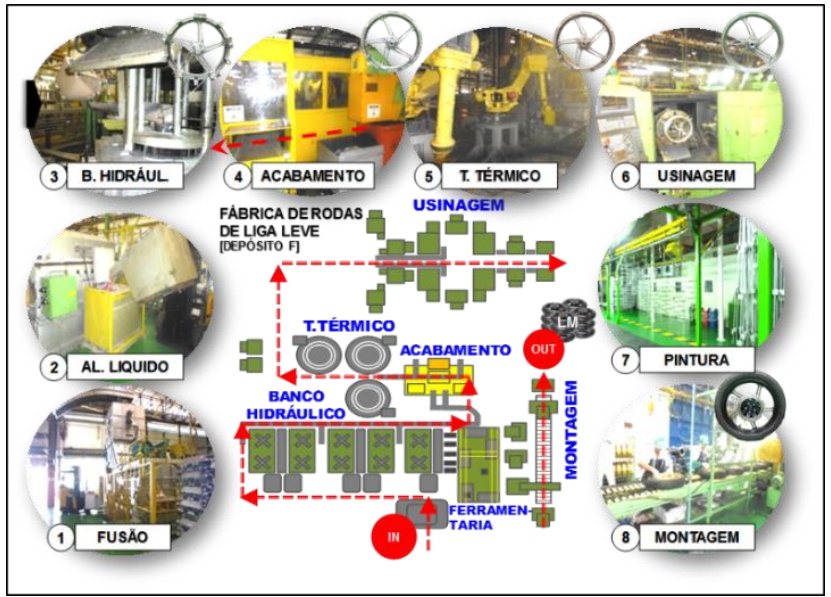

Figura 1: Processo de fabricação da roda liga leve. Fonte: Autores.

A Figura 2 ilustra as principais peças de reposição do molde da roda de liga leve. Para iniciar o processo de fabricação do molde, é desenvolvido um projeto, e cada peça tem sua finalidade, como: Copo de vazamento é o canal de alimentação do molde é ele quem recebe toda turbulência do alumínio e é a segunda peça a entrar em contato com o alumínio liquido; em seguida vem o inserto do massalote, são "reservatórios" de metal líquido para alimentar a contração em várias regiões do fundido, é a última parte a ser solidificada [12]; o inserto superior é responsável de formar o centro da roda, ali será encaixado o disco de freio; a bucha e a coluna guia, formam um conjunto e juntas impedem que a parte superior e inferior do molde desalinhem [14]; o inserto inferior aloja o macho de areia, deixando uma cavidade oca no interior da roda. Todas as peças de reposição e as demais, são fabricadas de aço VH13, mais utilizado entre os aços para trabalho a quente [13].

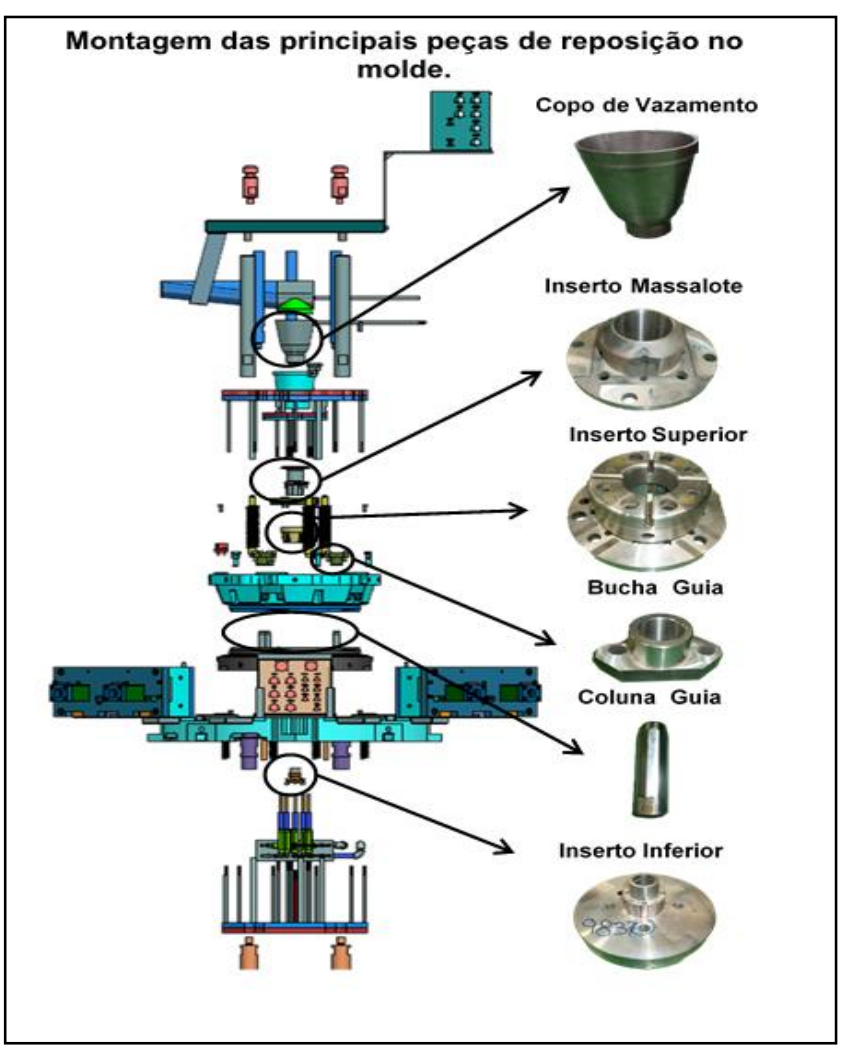

Figura 2: Desenho do molde da roda, destacando as principais peças de reposição.

Fonte: Autores. 
Para identificar possíveis falhas no processo de fundição da roda de liga leve, através digrama de Ishikawa, que procura assim a tecnologia que possa efetuar o controle preventivo, qualidade, custo e produtividade são efeitos ou resultados deste controle de processo [15]. Foram analisados os seguintes indicadores: Qualidade, Custo, Logística, Gerenciamento, Segurança e Meio Ambiente, apontados na Figura 3.

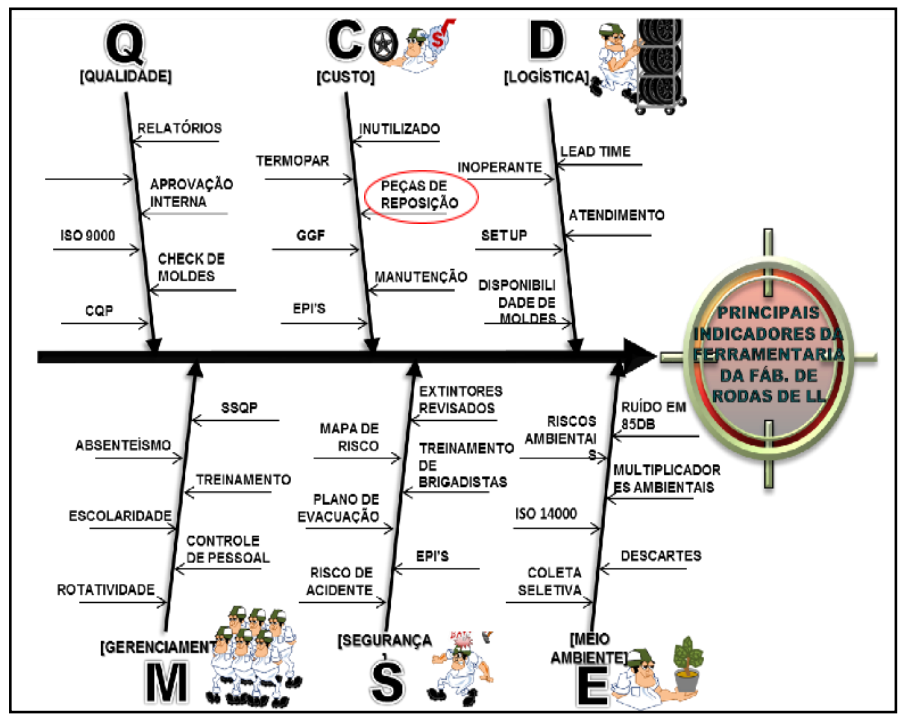

Figura 3: Diagrama de Ishikawa, utilizado para levantar causa raiz de um problema.

Fonte: Autores, 2019.

Com base nas análises feitas no diagrama de Ishikawa, notou-se que tinha um custo muito elevado com peças de reposição dos moldes da roda. Para melhor analisar esses custos apontados pelo diagrama, consultou-se os históricos de manutenções realizadas nos moldes, afim de detectar quais peças estavam elevando os custos com peças de reposição, para priorizar e ordenar as frequências das ocorrências, criou-se o Gráfico de Pareto [16].

A Figura 4 expõe o Gráfico de Pareto e tem por objetivo analisar o consumo anual de peças de reposição, evidenciando o copo de vazamento com $60 \%$ do índice indicado pelo gráfico.

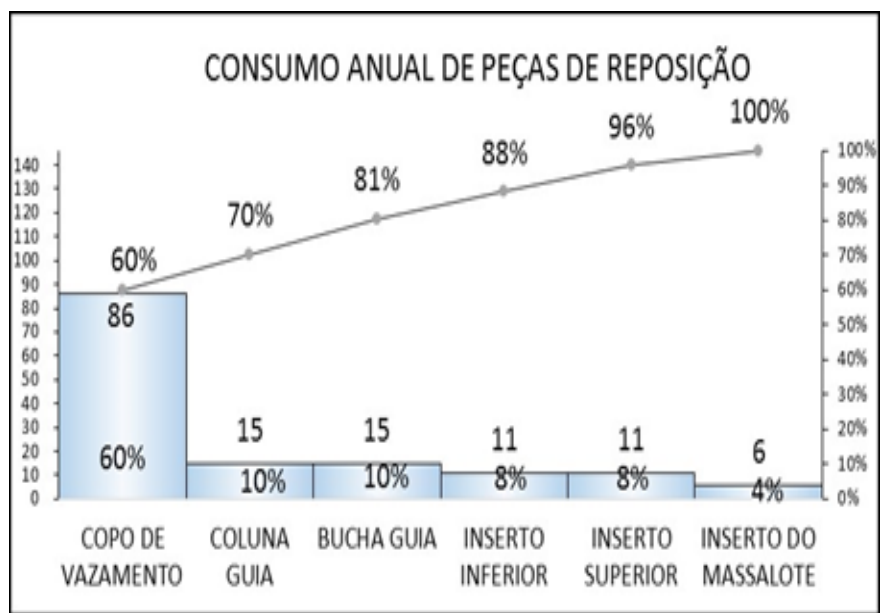

Figura 4: Análise de consumo anual de peças de reposição. Fonte: Autores, 2019.

Assim como o consumo, os custos anuais de peças de reposição também foram analisados, Pareto apontou novamente o copo de vazamento, tendo um custo de $\mathrm{R} \$ 395.600,00$ por ano, destacados na Figura 5.

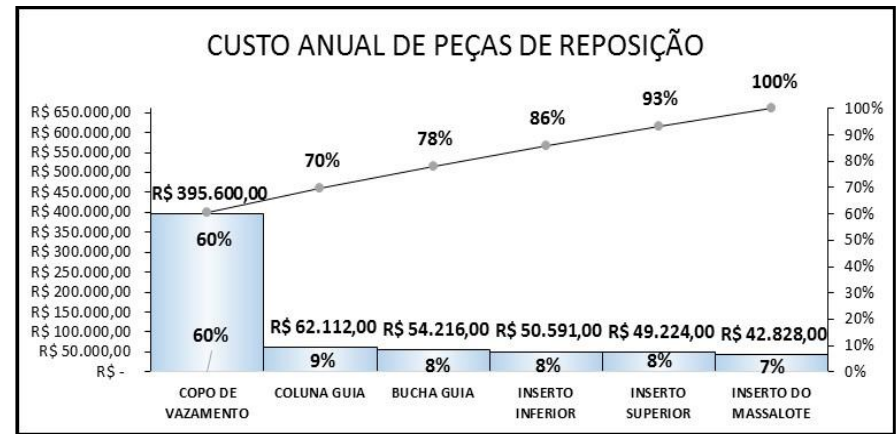

Figura 5: Análise de custo anual de peças de reposição.

Fonte: Autores, 2019.

Com o propósito de saber o motivo do copo estar com índices de consumo e custos elevados, foram avaliados as quantidades de ciclos que o copo produzia e detectou-se que após a produção de 2 (duas) mil peças o copo desgastava, conforme evidenciado na figura 6.

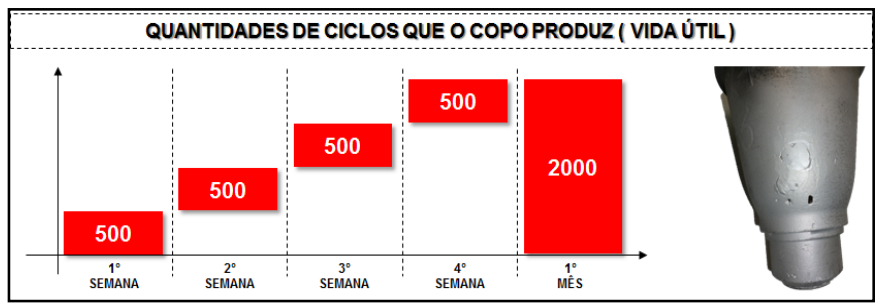

Figura 6: Quantidade de ciclos que o copo produz.

Fonte: Autores, 2019.

O diagrama de 4M's que tem o mesmo intuito do Ishikawa, que visa analisar a máquina, o método, o material e mão de obra [23], foi utilizado para checar o desgaste do copo, chegando à conclusão que teria que investigar o material, pois não foi encontrado nenhuma falha nos outros indicadores e, como mostra a Figura 7.

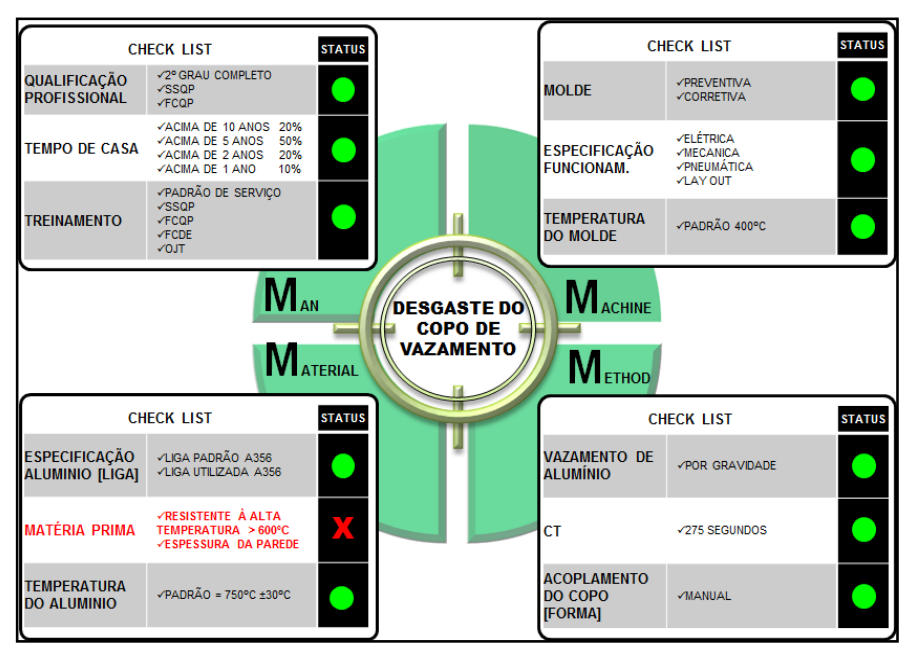

Figura 7: Análises do diagrama de 4 M's. Fonte: Autores, 2019.

Averiguou-se o material do copo, que é o aço VH13. Segundo [7] o aço VH 13 consegue manter suas propriedades sem sofrer deformações até uma temperatura de $600{ }^{\circ} \mathrm{C}$.

A temperatura de fusão do alumínio é de $660^{\circ} \mathrm{C}$ [5], mas devido à perda de temperatura durante o processo e para evitar que o alumínio solidifique antes de preencher totalmente a cavidade do molde, é necessário que seja depositado com uma temperatura de 
$730{ }^{\circ} \mathrm{C}$, evitando possíveis falhas e defeitos na estrutura da roda fundida.

A temperatura em torno de $700^{\circ} \mathrm{C}$, promove o aquecimento da superfície do molde ocasionando trincas e fadigas térmicas. Com base nessas análises observou-se que a temperatura do alumínio, o ciclo elevado de produção e a turbulência gerada na hora em que o alumínio é depositado no molde, ocasionam a fadiga e consequentemente o desgaste prematuro do copo [2]. Como exposto na Figura 8.

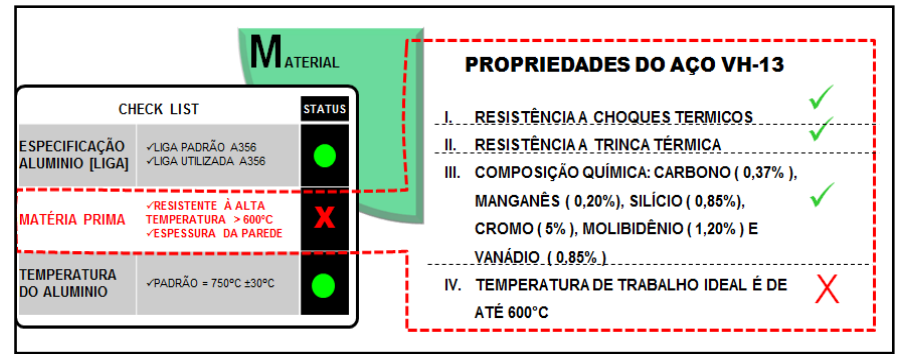

Figura 8: Análises das propriedades do copo de vazamento. Fonte: Autores, 2019.

Partindo do ponto em que o aço VH 13 não possui propriedades mecânicas capazes de evitar a fadiga e o desgaste prematuro do copo de vazamento, e tendo uma temperatura de trabalho de no máximo $600{ }^{\circ} \mathrm{C}$, foram realizados estudos e pesquisas bibliográficas com a finalidade de encontrar um material que fosse capaz de suportar trabalhar com elevadas cargas cíclicas e temperaturas acima de $730^{\circ} \mathrm{C}$, dentre os materiais encontrados destacou-se o ferro fundido.

\section{RESULTADOS E DISCUSSÕES}

Os ferros fundidos são materiais indicados para fabricação de discos de freio [22], [4] fala que a operação nos discos de freios podem alcançar valores em torno de $800^{\circ} \mathrm{C}$, sem perder as propriedades mecânicas. Chegando à conclusão que o Ferro fundido tem propriedades suficientes para trabalhos à uma temperatura de $800^{\circ} \mathrm{C}$.

Fundamentados nas apurações obtidas, o material de fabricação do copo de vazamento, foi alterado de AÇO VH13 para Ferro Fundido

Com o trabalho implantado, conseguiu-se reduzir em $88 \%$ do custo anual com fabricação do copo, passando de $\mathrm{R} \$ 395.500,00$ de custo com consumo de peças de reposição, para $\mathrm{R} \$ 47.120,00$. Expostos na Figura 9.

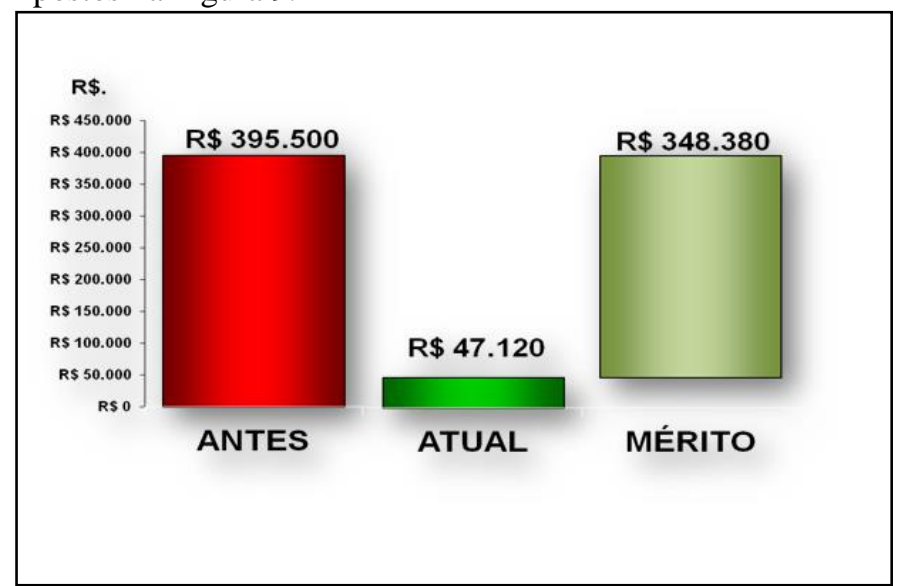

Figura 9: Comparativo dos custos antes e depois da implantação. Fonte: Autores, 2019.
Para obter esse resultado, o tipo de fabricação do copo mudou de aço VH 13, para ferro fundido, e também o tipo de processo de fabricação mecânica, antes o copo era totalmente usinado, para isso usava-se um tarugo de 2" de diâmetro, elevando o custo de fabricação de um único copo, devido o tempo elevado com usinagem de material para poder chegar nas dimensões desejada. Agora o copo passou a ser fundido. Foi feito um molde de areia nas dimensões aproximadas, expresso na Figura 10, com pouco desperdício de material e diminuindo o custo com fabricação do copo de $\mathrm{R} \$ 4.600,00$ para $\mathrm{R} \$ 1.240,00$.

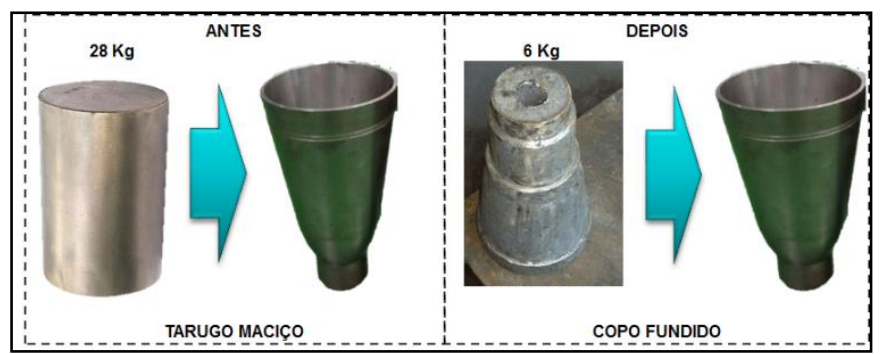

Figura 10: Comparativo de antes e depois da matéria prima usada para fabricar o copo.

Fonte: Autores, 2019.

Com a mudança de matéria prima, obteve-se um aumento da qualidade do copo, que antes era trocado a cada mês ou 2 mil peças produzidas, agora passou a ser trocado a cada seis meses ou 12 mil peças produzidas, devido à alta resistência ao desgaste do ferro fundido e a resistência a alta temperatura. Salientados na Figura 11.

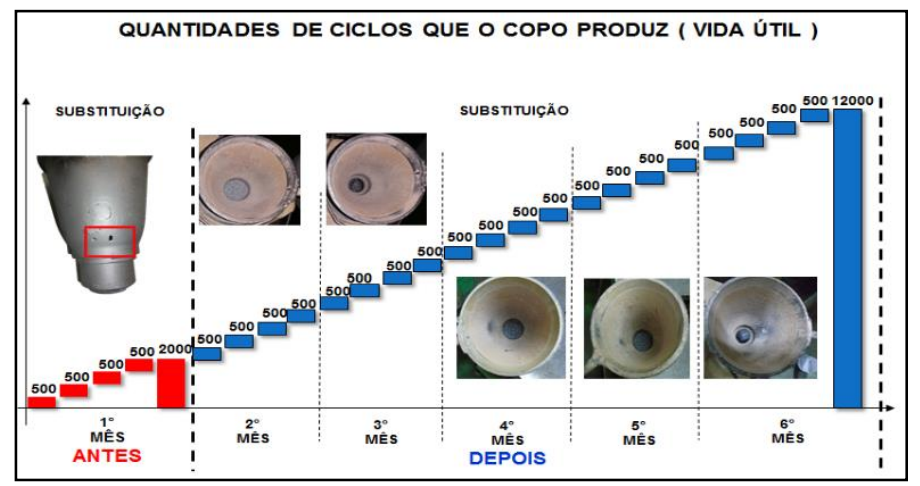

Figura 11: Análise feita mensalmente do copo depois da implantação do projeto.

Fonte: Autores, 2019.

A análise foi feita mensalmente, e constatou-se que o copo só apresentou desgaste depois de 12 mil peças produzidas.

A implantação do projeto teve ganhos significativos no meio ambiente, porque antes do projeto ser implantado, o copo era feito apenas com um processo que era usinagem. Para confeccionar o copo era usado um tarugo maciço de duas polegadas com um peso de $28 \mathrm{Kg}$, depois de implantar o projeto o copo semiacabado pesa apenas $6 \mathrm{Kg}$, reduzindo a quantidade de geração de resíduos, tendo uma redução de 2 toneladas por ano, além de reutilizar disco de freio de caminhão para a confecção do copo.

\section{CONCLUSÃO}

Todo material tem propriedades diferentes, e cada um é indicado para determinado tipo de processo. O aço VH 13 é um material específico para fundição de alumínio, mas sua temperatura de trabalho é de no máximo $600^{\circ} \mathrm{C}$, com isso a temperatura do 
alumínio de $730^{\circ} \mathrm{C}$, fazia com que o aço sofresse deformações e o desgaste precoce, devido à alta temperatura e os ciclo elevados de produção. $\mathrm{O}$ ferro fundido é indicado para temperaturas mais elevadas, é mais resistente devido o teor de carbono ser maior do que o do aço, sendo assim o material do copo foi alterado de aço VH 13 para ferro fundido, elevando seu desempenho.

A implantação do projeto trouxe diversos resultados positivos para a empresa, diminuindo em $88 \%$ o custo anual com fabricação do copo de vazamento, além de reduzir o desperdício de matéria prima, obtendo uma redução de $90 \%$ de geração de resíduos, porém o que mais impactou foi o aumento da resistência do copo de vazamento, saindo de uma vida útil de 2 mil peças, para 12 mil, um ganho de mais de $500 \%$ na vida útil do mesmo.

\section{REFERÊNCIAS BIBLIOGRÁFICAS}

[1]
Fundição.
Disponível
em:

$<$

https://www.infoescola.com/quimica/fundicao/ > Acesso em: 2019 abr. 2019.

[2] Tecnologia em metalurgia e materiais, são paulo, v.3, n.3, p. 63-68, jan.-mar. 2007. Disponível em: < https://www.researchgate.net/profile/Celso Barbosa3/publication/ 237786760_NOVO_ACO_FERRAMENTA DE_ALTA_RESIS TENCIA A QUENTE/links/56aa4c5908ae7f592f0f31f5/NOVOACO-FERRAMENTA-DE-ALTA-RESISTENCIA-A-

QUENTE.pdf > Acesso em: 2019 abr. 2019.

[3] Braghetto, Antônio. et al. Processos de fabricação. v.1. São Paulo: Globo, 2000.

[4] Limpert, R. Brake Design E Safety. Warrendale: Ed. SAE Interbational, 1999.

[5] Chiaverini, Vicente. Tecnologia Mecânica. Processos de Fabricação e Tratamento. 2a edição. Volume II. São Paulo, 1986. Editora McGraw-Hill Ltda. ISBN: 0074500899.

[6] MOREIRA, Marcelo F.; FUOCO, Ricardo. Materiais de construção mecânica: Ligas de alumínio fundidas. Disponível em: $<$

http://repositorio.roca.utfpr.edu.br/jspui/bitstream/1/8210/1/PB_D AMEC_2017_1_08.pdf >. Acesso em: 2019 abr. 2019.

[7] Propriedades do aço vh13. Disponível em:< https://www.ggdmetals.com.br/produto/aisi-h13/ > acesso em: 2019 mai. 2019.

[8] Avaliação experimental dos efeitos da fadiga térmica nas propriedades mecânicas de um aço inoxidável austenítico. Disponível em:

http://www.bibliotecadigital.ufmg.br/dspace/bitstream/handle/184 3/sbps-7b4pp2/tese_alvaro_alvarenga_ir.pdf?sequence $=1>$ acesso em: 2019 mai. 2019.

[9] North American die casting association. business solutions based on nadca research. die materials \& tecnologies. wheeling. il: nadca, 2009.

[10] Pelllizzare, M. MolinarI, A. Straffelini, G.- Thermal Fatigue Resistance of Plasma Duplex-Treated Tool Steel. Surface \& Coatings Technology. Vol 142, 2001 pag. 1109-1115.
[11] Olvera O., Barrow G., 1996. An experimental study of burr formation in square. International Journal of Machine Tools and Manufacture, Vol. 36 (1996) 1005-1020.

[12] Ligas de alumínio para fundição. Disponível em: : < http://www.pmt.usp.br/pmt3402/material/ligas_aluminio_fundida s.pdf $>2019$ mai. 2019.

[13] Estudo do comportamento tribológico do aço aisi h13 submetido a tratamento termoquímico de boretação. Disponível em:

http://www.tede.udesc.br/bitstream/tede/1509/1/Anael\%20Krellin g.pdf > Acesso em: 2019 mai. 2019.

[14] Saca pino pneumático. Disponível em: < http://lyceumonline.usf.edu.br/salavirtual/documentos/2951.pdf > Acesso em: 2019 mai. 2019.

[15] Ishikawa, k. Controle de qualidade total: à maneira japonesa. Rio de Janeiro: Campos, 1993. P. 79

[16] Aplicação do isa e diagrama de pareto como ferramentas de gestão do loteamento lagoa carapebus. Disponível em: < https://www.lajbm.net/index.php/journal/article/view/120/73 > Acesso em: 2019 mai. 2019.

[17] Aplicação de ferramentas de melhoria de qualidade eprodutividade nos processos produtivos: um estudo de caso Disponível em:

http://revista.uepb.edu.br/index.php/qualitas/article/view/1599/92 4 > Acesso em: 2019 mai. 2019.

[18] Vieira, s. estatística para a qualidade: como avaliar com precisão a qualidade em produtos e serviços.rio de janeiro: campus, 1999.

[19] Ramos, a.w. cep para processos contínuos e em bateladas. São Paulo: Fundação Vanzolini, 2000.

[20] Kume, h. Métodos estatísticos para melhoria da qualidade. 11. ed. São Paulo: Editora Gente, 1993. 245 p.

[21] Werkema, m.c.c. As ferramentas da qualidade no gerenciamento de processos. 2. ed. Belo Horizonte: UFMG; Fundação Christiano Ottoni, 1995. 108 p.

[22] Fadiga termomecânica em ligas de ferro fundido cinzento para discos de freio automotivos Disponível em: < http://www.teses.usp.br/teses/disponiveis/88/88131/tde-

23062009-151607/en.php > Acesso em: 2019 mai. 2019.

[23] Análise de melhoria contínua na preparação de kit em uma fábrica de motores Disponível em: < http://repositorio.roca.utfpr.edu.br/jspui/bitstream/1/10327/1/PB_ DAMEC_2018_1_03.pdf > Acesso em: 2019 mai. 2019. 